\title{
The Expression of p53 as a Reliable Immunohistochemical Marker for Clinicopathological Correlation of Gastric Adenocarcinomas
}

\author{
${ }^{1}$ Srikumar Chakravarthi, ${ }^{2}$ Ang Seng Long, ${ }^{2}$ Beh Hannien, \\ ${ }^{1}$ Thani Pasupati, ${ }^{3}$ Kandasamy Palayan and ${ }^{4}$ Arni Talib \\ ${ }^{1}$ Department of Pathology, Faculty of Medicine, International Medical University, Malaysia \\ ${ }^{2}$ Research Lab, Department of Post Graduate Studies, International Medical University, Malaysia \\ ${ }^{3}$ Department of Surgery, Clinical School, International Medical University, Malaysia \\ ${ }^{4}$ Department of Pathology, Hospital Tuanku Jaafar, Seremban, Malaysia
}

\begin{abstract}
For evaluation of the prognostic relevance of p53 expression in gastric cancer, the immunohistochemical tissue status of 66 primary gastric cancer patients was investigated for p53 expression and the association between p53 tissue status and clinicopathological parameters was analyzed. p53 immunoreactivity was detected in the nuclei of cancer cells in 42 cases (63.7\%). The nuclear p53 immunoreaction was closely associated with tumour location, lymph node metastasis and curability. Tumours with positive p53 stain reactions frequently metastasized to lymph nodes (metastatic rate: $88.3 \%$ ) in contrast to tumors with negative p53 stain reactivity $(59.4 \%, \mathrm{p}<0.005)$. Immunohistochemical analysis of primary gastric cancer appears to be an accurate and simple method of screening for p53 expression. In combination with common prognostic parameters, determination of p53 tissue status might help to detect prognostically unfavourable subgroups of gastric cancer patients.
\end{abstract}

Key words: p53, immunohistochemistry, gastric adenocarcinoma, tumours, nuclei, lymph node

\section{INTRODUCTION}

In the last several years, developments in molecular genetics have shown that the accumulation of multiple genetic alterations, e.g., activation of oncogenes and inactivation of tumour-suppressor genes, results in cancer development in various organs (Fearon and Vogelstein, 1990). Mutation and amplification of oncogenes and tumour-suppressor genes have been reported in gastric cancer tissue and cell lines (Tahara, 1993). It has been shown that the p53 gene is a tumour-suppressor gene Finlay et al. (1990) and its mutations play an important role in the development of human malignancies (Soussi et at., 1994). The tumour-suppressor $\mathrm{p} 53$ gene is located on chromosome $17 \mathrm{p}$, whereby the wild-type p53 has been implicated in the control of the cell cycle, Deoxyribonucleic Acid (DNA) repair and synthesis, cell differentiation, genomic stability and apoptosis (Schneider et al., 1996).

In contrast to cancers such as colorectal and breast carcinomas, there is a large gap in the understanding of the molecular mechanisms of initiation and progression of gastric cancer (Carneiro et al., 1994). Few reports have focused on the relation between p 53 tissue status and the degree of malignancy of gastric cancer.
Immunohistochemical studies show that antibodies raised against mutant p53 proteins may be used as screening method for the presence of mutations, because of accumulation of p53-associated protein in the mutant type.

Therefore, the intent of the present immunohistochemical study is to determine to what extent histopathological findings and clinical outcomes are resected in the p53 tissue status of patients with resectable gastric cancer.

\section{MATERIALS AND METHODS}

Patients: This study included 66 patients with primary gastric cancer, all of whom underwent gastrectomy with D-2 lymph node dissection at the Department of Surgery of the teaching hospital of the Medical University, from 2004-2006.

Pathological diagnosis and classification of the resected gastric tissues were made according to the UICC TNM system.

Immunohistochemical staining of p53: All tumour specimens were fixed in $10 \%$ formaldehyde and embedded in paraffin. The $4 \mu \mathrm{m}$ thick sections were cut from the

Corresponding Author: Srikumar Chakravarthi, Department of Pathology, Faculty of Medicine, International Medical University, Malaysia 


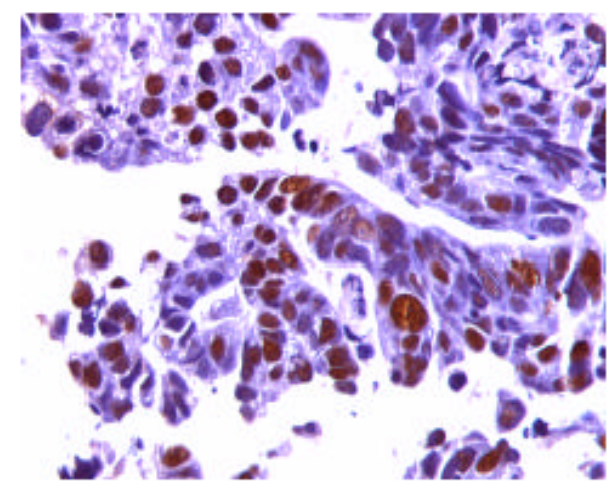

Fig. 1: Photomicrograph of a pootly differentiated gastric adenocarcinoma showing positivity for p53 in the nuclei of pleomorphic malignant cells (IHC, 400x)

paraffin blocks containing representative histological features from the periphery, the centre and the invasion front of the tumour (three slides per patient). Paraffin was removed from the sections in xylene for $30 \mathrm{~min}$. After hydration the sections were placed in Phosphate Buffered Saline (PBS) at $\mathrm{pH} 7.4$ and $2 \%$ normal porcine serum to was applied in order to abolish nonspecific binding of the primary antibody.

The slides were then incubated with the monoclonal antibody Do-7 (Dako Diagnostica, Gemany) ovemight at $4^{\circ} \mathrm{C}$ (dilution 1:30). This antibody recognizes both wild and mutant forms of the p 53 protein. In the next step, the slides were incubated with abiotinylated secondary rabbit anti-mouse antibody and the streptavidin-biotin-alkaline phosphatase complex (both from Dako) according to the $\mathrm{ABC}$ method.

The colour reaction for the alkaline phosphatase was developed in $70 \mathrm{~mL}$ Tris buffer ( $\mathrm{pH}$ 8.2) enclosing $14 \mathrm{mg}$ naphthol-AS-MX phosphate (Sigma, Munich, Germany) and $14 \mathrm{~mL}$ dimethylformamid (Merck, Darmstadt, Germany).

In a second step, $16.8 \mathrm{mg}$ levamisol and $70 \mathrm{mg}$ Fast Red TR Salt (both Sigma) were added. Weak nuclear counterstaining was performed with hematoxylin. Incidences of nuclear accumulation of $p 53$ protein were determined for each histopathological group (Fig. 1), as were depth of tumour invasion, microscopic lymphatic and venous invasion, lymph node status and clinicopathological stage of disease. A stain was considered positive, when $20 \%$ of the cancer cells showed a positive nuclear staining (Fig. 2).

Statistical analysis: Kaplan-Meier survival curves of survival periods were analyzed by the generalized Wilcoxon test. The $\chi^{2}$-test was used for testing

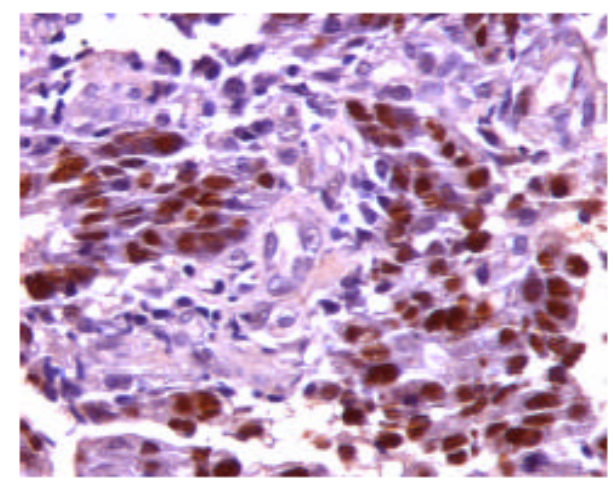

Fig. 2: Photomicrograph of a moderately differentiated gastric adenocarcinoma showing diffuse cellular areas of 53 positivity in the nuclei of the tumour cells (IHC, 400x)

differences with $\mathrm{p}<0.05$. Cox regression analysis was used to estimate the independent predictive value of the variables. All calculations were performed using the statistical software SPSS vercion 16.

\section{RESULTS}

In 66 unselected primary gastric carcinomas, we compared common prognostic markers such as age, sex, tumour location, Lauren (1965) type, B orrmann classification, tumour grading, TNM system, curative resection and p53 expression. The tumours examined in this study were separated into two groups, based upon the percentile of p53-protein-positive cell nuclei. A total of 42 tumours (63.7\%) stained positive for $p 53 ; 24$ tumors with a p53 protein expression of $<20 \%$ were treated as negative results.

There was no obvious relation between p53 staining and the age or sex of the patients. No significant correlations were found between p53 tissue status and Bormann classification, Lauren (1965) type, tumour grading and depth of invasion ( $T$ status).

In contrast, there was a significant association between p53 tissue status and the metastatic spread to lymph nodes. p53 positive tumours were associated with a higher incidence of metastasis to $1 \mathrm{ymph}$ nodes $(88.3 \%)$ than were p53 negative tumors $(59.4 \% ; \mathrm{p}<0.005)$. There was a significant association between p53 tisuse status and metastasis to the liver and peritoneal dissemination $(\mathrm{p}<0.004)$.

Significant discrepancies were noted among the p53 positive tissue specimens with elevated preoperative ASA dassification (American Society of Anaesthesi ologists) rick profiles. Furthemore, differences were also noted in tumour location. p53-positive tumours 


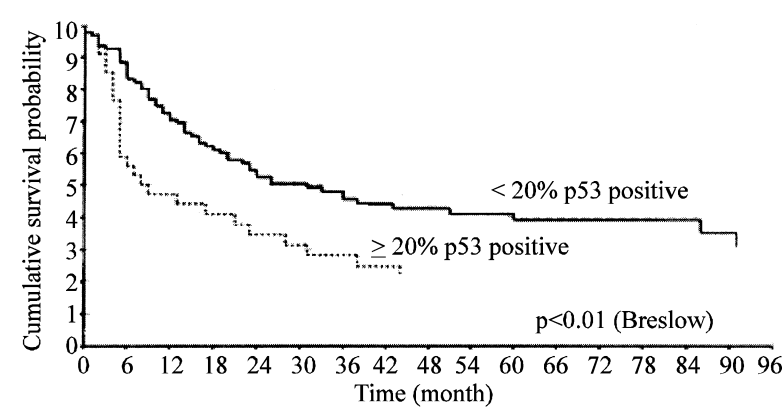

Fig. 3: Kaplan Meier survival analysis of p53 expression in gastric cancer

were more common in the upper third of the stomach dispersed across multiple segments of the stomach. The 30 -days lethality rates measured $3.0 \%$ for $\mathrm{p} 53$ negative patients and $3.1 \%$ for $\mathrm{p} 53$ positive patients $(\mathrm{p}<0.005)$. Five-year survival was $39.2 \%$ for the $\mathrm{p} 53$ negative group and $21.0 \%$ for the p53 positive group. Mean survival durations averaged $55.6+/-5.3$ months (SD) for p53negative patients and 30.6+/-6.2 months among p53positive patients (Fig. 3).

The analysis of p53 tissue status and survival figures revealed that patients with $\mathrm{p} 53$-negative tumours survived significantly longer than those with $\mathrm{p} 53$ positive tumours $(\mathrm{p}<0.01)$. Cox's proportional hazard mode 1 was used to test the factors.

The analysis showed that the preoperative ASA classification risk profile, nodal status, remote metastases (M status) and the extent of surgical resection ( $\mathrm{R}$ status) were all independently significant predictors of survival prognosis.

Thus, in this study, p53 tissue status proved to be an independently significant predictor of survival prognosis.

\section{DISCUSSION}

Although, gastric cancer is the most common form of gastrointestinal malignancy in certain parts of the world, relatively little is known about the molecular occurrences leading to its development. Nodal status and curative resection are widely accepted as the most important prognostic factors in gastric cancer to date.

Recent data have shown that allelic loss of chromosome $17 \mathrm{p}$ and mutations of the p53 gene are common in certain human tumours, including lung and colon tumors (Kim et al., 1991). In contrast, the significance of $\mathrm{p} 53$ expression in gastric carcinomas remains a point of controversy and few initial studies have described a correlation between increased p53 expression and reduced survival rates (Starzynska and Bromery, 1992).

Therefore in this study, immunohistochemical examination methods were employed to investigate p53 expression in resected gastric cancer specimens. With regards to the frequency of p53 mutation in gastric cancer, Fushida (1992) reported that four of nine (44\%) gastric cancer cell lines showed point mutations in atleast one of the most highly conserved regions in the p53 gene. Tamura et al. (1991) detected p53 mutations in exons $4 \pm 8$ in $64 \%$ ( 9 of 14) of cases following tumour cell enrichment by cell sorting using flow cytometry. Martin et al. (1992) reported a rate of 57\% p53 immunohistochemically positive specimens in a gastric cancer collective and Yonemura et al. (1993) found rates of $32 \%$ in their investigations.

Kakeji et al. (1993) found positive p53 staining in 54\% of cases. He defined all specimens with $>10 \%$ positive nuclear staining as p53 positive. In the present study, $26.3 \%$ of the gastric cancers were considered $\mathrm{p} 53$ positive ( $>20 \%$ of cancer cells staining positive).

One explanation for the significant results can be derived from differences in immunohistochemical techniques employed and p53 antibodies used. p53 gene mutations were observed in $40 \%$ of advanced gastric cancers of the intestinal type, but less frequently in the diffuse type. No significant differences were found in p53 tissue status between intestinal and diffuse type in this study. A significant correlation of p53 positive tissue status and tumour location in the upper third of the stomach was not confirmed in other studies (Ochiai et al., 1996).

As (Carneiro et al., 1994; Tamura et al., 1991), no correlation was found between positive p53 tissue status and histological grade of tumor differentiation. Kakeji et al. (1993) showed that tumours with p53 positive staining had a higher proliferative activity than did those that stained negative.

Additionally, Yonemura et al. (1993) was able to document increased proliferation levels in p53 positive tumours. In the own collective, lymph node metastases were found significantly more frequently among p53 positive tumors $(\mathrm{p}<0.001)$. This observation was confirmed in studies by Yonemura et al. (1993) and Kakeji et al. (1993).

The prognostic advantage of p53 negative tumours over p53 positive tumours with significantly shorter survival rates as found in nonvariant analyses could be confirmed in variant analysis. A possible explanation for 
this phenomenon may be found in the significantly increased ASA classification risk profile found in the p53 positive tumour group.

Even Kakeji et al. (1993) found a significant difference between $\mathrm{p} 53$ positive and negative tumours with regard to survival rates.

The study of Yonemura et al. (1993) demonstrated that patients with $\mathrm{p} 53$ negative tumours had a significant survival advantage compared to p53 positive tumour patients and that p53 tissue status combined with conventional prognostic factors is an independent prognostic indicator for gastric cancer.

\section{CONCLUSION}

Immunohistochemical analysis of primary gastric cancer appears to be an accurate and simple method screening the presence of mutant p53 protein (Seruca et al., 1992; Yonemura et al., 1993). This study was able to demonstrate that p53 immunoreactivity in gastric cancer is closely associated with lymph node metastasis.

Therefore, data on the immunhistochemistry of p53 expression in gastric cancer may be clinically useful in obtaining information on the metastatic potential to lymph nodes and additionally in determining the therapeutic treatment of these patients.

\section{ACKNOWLEDGEMENT}

This study was done partly under a research grant provided by the International Medical University, Kuala Lumpur, Malaysia.

\section{REFERENCES}

Carneiro, F., L. David, M. Sobrinho-Simoes, R. Seruca and J.M. Nesland, 1994. Oncogenes and onco suppressor genes in gastric carcinoma. Surg. Pathol., 5 (3): 225-238. DOI: 10.1136/gut.33.8.1033. PMCID: PMC1379437. http://www.ncbi.nlm.nih. gov/pmc/articles/PMC1379437/pdf/gut00575-0039. pdf.

Fearon, E.R. and B.A. Vogelstein, 1990. Genetic model for colorectal tumogenesis. Cell, 61: 759-767. DOI: 10.1016/0092-8674(90)90186-I. PMID: 2188735. http://www.charite.de/gastro/workgroups/ag _hanski/download/Fearon\%20and\%20Vogelstein. pdf.
Finlay, C.A., P.W. Hinds and A.J. Levine, 1990. The p53 protooncogene can act as a supressor of transformation. Cell, 157: 1083-1093. DOI: 10.1101/ SQB.1991.056.01.028. PMID: 2525423. http://linkinghub.elsevier.com/fulltext/pii/S0092867404000364.

Fushida, S., 1992. Frequent p53 mutations in human gastric cancer cell lines. J. Juzen Med. Soc., 101:147-154.DOI:10.1002/1097-0142(19950215)75:4< 920::AD-CNCR2820750405>3.0.CO;2-E. PMID: PMC2 063311.http://nels.nii.ac.jp/els/110006573386.pdf?id= ART0008556350\&type $=$ pdf\&lang $=$ en\&host $=$ cinii\& order_no $=\& p p v \_t y p e=0 \&$ lang_sw $=\& n o=12584488$ 86\&cp.

Kim, J.H., T. Takahashi, J. Chiba, J.G. Park, M.J. Birren, J.K. Roh, H. Delee, J.P. Kim, J.D. Minna and A.F. Gazdar, 1991. Occurence of p53 gene abnormalities in gastric carcinoma tumors and cell lines. J. Natl. Cancer Inst., 83 (13): 938-94. DOI: 10. 1111/j.1349-7006.1997.tb00405.x. PMID: 1676761. http://jnci.oxfordjournals.org/cgi/reprint/83/13/938.

Lauren, P., 1965. The two histological main type of gastric carcinoma: Diffuse and so-called intestinal type carcinoma. An attempt at a histoclinical classification. Acta Pathol. Microbiol. Scand, 64: 31-34. DOI: 10.1136/apms. 1965.038778. PMID: 1320675. http://www.garfield. library.upenn.edu/classics1993/A1993LQ46500001. pdf.

Ochiai, A., Y. Yamauchi and S. Hirohashi, 1996. p53 mutations in the non-neoplastic mucosa of the human stomach showing intestinal metaplasia. Int. J. Cancer, 69: 28-33. DOI: 10.1002/(SICI)1097-0215(19960220) 69:1<28::AID-IJC6>3.0.CO;2-Y. PMID: 8600055. http://www3.interscience.wiley.com/cgi-bin/fulltext/ 60261/PDFSTART.

Schneider, P.M., A.G. Casson, B. Levin, H.S. Garewal, A.H. Hoelscher, K. Becker, H.J. Dittler, K.R. Cleary, M. Troster, J.R. Siewert and J.A. Roth, 1996. Mutations of p53 in Barrett's esophagus and Barrett's cancer: A prospective study of 98 cases. J. Thorac. Cardiovasc. Surg., 111: 323-333. DOI: 10.1136/jtcs. 1996.034298. PMID: 8583805. http://jtcs.ctsnetjournals.org/cgi/content/full/111/2/323.

Seruca, R., L. David, R. Holm, J.M. Nesland, B.M. Fangan, S. Castedo, M. Sobrinho-Simoes and A.L. Borre Sen, 1992. p53 mutations in gastric carcinomas. Br. J. Cancer, 65: 708-710. DOI:10.1054/bjoc.1992.1355. PMCID: PMC1977375. http://www.ncbi.nlm.nih.gov/ pmc/articles/PMC1 977375/pdf/brjcancer000690078.pdf. 
Soussi, T., Y. Legros, R. Lubin, K. Ory and B. Schlichtholz, 1994. Multifactorial analysis of p53 alterations in human cancer: A review. Int. J. Cancer, 57: 1-9. DOI: 10.1002/ijc.2910570102. PMD: 8150526. http://www3.interscience.wiley.com/journal/fulltext/ 112717768.

Starzynska, T. and M. Bromery, 1992. Prognostic significance of $\mathrm{p} 53$ overexpression in gastric and colorectal carcinoma. Br. J. Cancer, 66: 558-562. DOI: 10.1038/sj.bjc.6690201. PMID:PMC2074579. http://www.ncbi.nlm.nih.gov/pmc/articles/PMC2074 579/pdf/brjcancer00018-0056.pdf.

Tahara, E., 1993. Molecular mechanism of stomach carcinogenesis. Cancer Res. Clin. Oncol., 119: 1-8. DOI: $10.1007 / \mathrm{BF} 01212724 . \quad$ PMID: 8440743. http://www.springerlink.com/content/x1 n08u3144 013864.
Tamura, G., T. Kihana, K. Nomura, M. Terada, T. Sugimura and S. Hirohashi, 1991. Detection of frequent p53 gene mutations in primary gastric cancer by cell sorting and polymerase chain reaction single-strand conformation polymorphism analysis. Cancer Res., 51:3056-3058.DOI:10.1111/j.1349-7006.1995.tb03031. PMID: 2032245. http://cancerres.aacrjournals.org/cgi/ reprint $/ 51 / 11 / 3056$.

Yonemura, Y., A. Fushida, K. Tsugawa, I. Ninomiya, L. Fonseca, A. Yamaguchi, I. Miyazaki, T. Urano and H. Shiku, 1993. Correlation of p53 expression and proliferative activity in gastric cancer. Anal. Cell. Pathol., 5: 277-288. DOI: 10.1007/s004320050205. PMID: 8105878.http://www.springerlink.com/content/ rbclb6r9ejgmlq5e/fulltext.pdf. 